\title{
Post-surgical follow-up (by ELISA and immunoblotting) of cured versus non-cured cystic echinococcosis in young patients
}

\author{
N. BEN NOUIR ${ }^{1}$, S. NUÑEZ ${ }^{2}$, E. FREI ${ }^{2}$, M. GORCII ${ }^{1}$, N. MÜLLER ${ }^{2}$, C. GIANINAZZI ${ }^{2}$, \\ M. MEKKI ${ }^{3}$, A. NOURI ${ }^{3}, \mathrm{H} . \mathrm{BABBA}^{1}$ and B. GOTTSTEIN ${ }^{2 *}$ \\ ${ }^{1}$ University of Monastir, Faculty of Pharmacy, Department of Clinical Biology B, Laboratory of Parasitology and Mycology, \\ 99UR/08-05 1- rue Avicenne, 5000 Monastir Tunisia \\ ${ }^{2}$ Institute of Parasitology, University of Bern, Längass-Strasse 122, CH-3001 Bern, Switzerland \\ ${ }^{3}$ E. P. S. Fattouma Bourguiba, Pediatric Surgery Service, Monastir 5000, Tunisia
}

(Received 10 Fanuary 2007; revised 15 March and 27 Fune 2007; accepted 4 Fuly 2007; first published online 4 September 2007)

\section{S U M MAR Y}

The study was designed to determine comparatively the prognostic value of immunoblotting and ELISA in the serological follow-up of young cystic echinococcosis (CE) patients exhibiting either a cured or a progredient (non-cured) course of disease after treatment. A total of 54 patients (mean age 9 years, range from 3 to 15 years) with surgically, radiologically and/ or histologically proven $\mathrm{CE}$ were studied for a period up to 60 months after surgery. Additionally, some of the patients underwent chemotherapy. Based on the clinical course and outcome, as well as on imaging findings, patients were clustered into 2 groups of either cured (CCE), or non-cured (NCCE) CE patients. ELISA showed a high rate of seropositivity 4 to 5 years post-surgery for both CCE $(57 \cdot 1 \%)$ and NCCE $(100 \%)$ patients, the difference found between the two groups was statistically not significant. Immunoblotting based upon recognition of $\mathrm{AgB}$ subcomponents ( 8 and $16 \mathrm{kDa}$ bands) showed a decrease of respective antibody reactivities after 4 years post-surgery. Only sera from $14 \cdot 3 \%$ of CCE patients recognized the subcomponents of $\mathrm{AgB}$ after 4 years, while none $(0 \%)$ of these sera was still reactive at 5 years post-surgery. At variance, immunoblotting remained positive for $\mathrm{AgB}$ subcomponents in $100 \%$ of the NCCE cases as tested between 4 and 5 years after surgical treatment. Immunoblotting therefore proved to be a useful approach for monitoring post-surgical follow-ups of human $\mathrm{CCE}$ and NCCE in young patients when based upon the recognition of AgB subcomponents.

Key words: Echinococcus granulosus, cystic echinococcosis, serology, ELISA, immunoblotting, long-term follow-up.

\section{INTRODUCTION}

Hydatidosis or cystic echinococcosis (CE) is a zoonosis caused by infection with the larval stage of the cestode tapeworm Echinococcus granulosus. The parasite has a cosmopolitan distribution with a high prevalence documented in some areas such as North Africa, Australia and South America (Eckert et al. 2000; McManus et al. 2003). In Tunisia, human $\mathrm{CE}$ is a public health concern with an annual surgical incidence estimated at 15 cases $/ 100000$ inhabitants (Ministère de la Santé Publique, 1993; OudniM'Rad et al. 2007). Diagnosis of CE is mostly based on clinical findings (X-ray, ultrasonography [US], computed tomography [CT] and magnetic resonance imaging $[\mathrm{MRI}])$. In certain cases immunodiagnosis is a useful support for the clinical diagnosis and to confirm the hydatid nature of the cyst (Babba et al. 1994). Approximately $10 \%$ of the CE cases occur in children, but in certain areas, e.g. in some countries

* Corresponding author: Institute of Parasitology, University of Bern, Längass-Strasse 122, CH-3001, Bern, Switzerland. Tel: +413163124 18. Fax: +4131631 24 77. E-mail: bruno.gottstein@ipa.unibe.ch of North Africa, the percentage of young patients may be much higher (Oudni-M'Rad et al. 2007).

Surgery is the treatment of choice, offering in certain cases a complete cure and recovery. However, in some cases of complicated cysts (such as fissured or super-infected), surgical procedures and inadequate cyst removal can lead to the spillage of parasite material including protoscoleces, which can be the origin of newly developing cysts and thus relapse of disease. Another post-surgical complication is the appearance of 'new' cysts not previously detected due to their size and/or localization.

One of the major problems of human $\mathrm{CE}$ encountered by clinicians is the frequency of relapses, affecting approximately $2-20 \%$ of cases after surgery according to WHO (2001) and 14-25\% of cases after chemotherapy, according to Franchi et al. (1999) and Pawlowski et al. (2001). Therefore, there is a need for evaluation of markers which could be used post-operatively, that allow rapid detection of newly growing or relapsing cysts. Many serological tests have been used for post-surgical or posttreatment follow-up of hydatidosis, including the indirect haemagglutination (IHA) test, the enzyme-linked immunosorbent assay (ELISA), and 
Table 1. Overview of the clinical features of the two groups of CE patients included in the present study

(For CCE patients, chemotherapy (albendazole, ABZ) was added to surgery when cysts were considered as fissured. In NCCE patients, ABZ was administered in cases exhibiting fissured cysts, multiple cysts, and disseminated or inoperable cysts left after surgery.)

\begin{tabular}{|c|c|c|c|c|c|c|c|c|c|c|c|c|c|}
\hline & \multirow[b]{2}{*}{$n$} & \multicolumn{2}{|c|}{ Sex } & \multirow[b]{2}{*}{$\begin{array}{l}\text { Age } \\
\text { (mean years) }\end{array}$} & \multicolumn{3}{|c|}{ Cyst localization } & \multicolumn{5}{|c|}{ Therapy } & \multirow[b]{2}{*}{$\begin{array}{l}\text { Follow-up } \\
\text { (years) }\end{array}$} \\
\hline & & $\mathrm{F}$ & M & & Lungs & Liver & Multiple* & $n$ & $\begin{array}{l}\text { Period } \\
\text { (months) }\end{array}$ & $\begin{array}{l}\text { Surgery } \\
\text { only }\end{array}$ & $\begin{array}{l}\text { ABZ } \\
\text { only }\end{array}$ & $\begin{array}{l}\text { Surgery } \\
\text { plus ABZ }\end{array}$ & \\
\hline $\begin{array}{l}\text { Cured } \\
\text { (CCE) }\end{array}$ & 40 & 16 & 24 & $9(3-15)$ & 18 & 11 & 11 & 6 & $2-48$ & 34 & 0 & 6 & $3 \pm 2$ years \\
\hline $\begin{array}{l}\text { Non-cured } \\
\text { (NCCE) }\end{array}$ & 14 & 4 & 10 & $9(4-14)$ & 5 & 6 & 3 & 9 & $12-60$ & 5 & 2 & 7 & $3 \pm 2$ years \\
\hline
\end{tabular}

* Multiple locations indicate cysts detected in the liver and the lungs (10 cases), liver and spleen (1 case), liver and mediastinum (1 case), liver, lungs and heart (2 cases).

immunoblotting (Force et al. 1992; Ravinder et al. 1997; Zarzoza et al. 1999; Gadea et al. 2000; Bulut et al. 2001 ; Doiz et al. 2001; Rigano et al. 2002; Lawn et al. 2004). Their usefulness for monitoring CE patients after surgery was variable among different laboratories, a fact that may be related to the type and procedure of antigen preparation used (Lightowlers and Gottstein, 1995). The period of time between surgery and serum collection is important with regard to the predictive value indicating either recovery or relapse. Few studies have been designed so far to evaluate modern immunodiagnostic tests for their predictive value after surgery, and/or chemotherapy (Moosa and Abdel-Hafez, 1994; Zarzosa et al. 1999; Rigano et al. 2002; Nasrieh and Abdel-Hafez, 2004). One promising approach was recently reported by Hernandez et al. (2005) who demonstrated a correlation between selected risk factors for CE and seropositivity using crude antigens of E. granulosus (ELISA) or purified antigen B. An improved immunodiagnostic performance was achieved using a synthetic peptide derived from the antigen B sequence (Gonzales-Sapienza et al. 2000). This peptide had not been evaluated for the post-operative follow-up of CE patients.

In the present study, we assessed ELISA and immunoblotting as tests for post-therapeutical follow-up of $\mathrm{CE}$ in young patients. Children and adolescents, when compared to adult CE patients, more frequently present immunodiagnostic problems post-operatively (WHO, 2001). Children not only represent the largest proportion of $\mathrm{CE}$ patients when clustered according to age distribution (WHO, 2001), but young patients also require special attention with regard to surgical and medical intervention (Dincer et al. 2006; Durakbasa et al. 2006). Also, in relatively high endemic areas such as Tunisia, CE commonly starts during childhood or adolescence (Oudni-M'Rad et al. 2007). The young CE patients participating in the present study were placed either into a cured (CCE) group of patients, which presented no signs of relapse for a period of up to $4-5$ years following initial treatment, or into a non-cured (NCCE) group who presented still active cysts at 4-5 years following initial treatment or diagnosis, and despite an initial attempt to curative surgery of the cysts in all but 2 of these cases.

MATERIALS AND METHODS

\section{Sera from CE patients}

A total of 290 sera were collected from 54 children or adolescents affected by $\mathrm{CE}$ (mean age 9 years, range 3 to 15 years). In each case a first sample was obtained at the time of diagnosis (prior to medical intervention, day 0 ) and further samples during a followup period ranging between 7 days and 5 years post-surgery and/or chemotherapy (Table 1). The intervals and numbers of follow up steps were variable between the patients, and the mean serum sample number per patient was $7 \pm 2$. All specimens were stored at $-20{ }^{\circ} \mathrm{C}$ prior to laboratory testing. For follow-up studies, all patients were subjected to serological and radiological investigation 1 week after surgery and/or start of chemotherapy, then 1 month, 6 months and subsequently once per year. Clinical and parasitological examinations were carried out at the E.P.S. Hospital of Monastir (Tunisia) in the Pediatric Surgery Service and in the Laboratory of Diagnostic Parasitology of Monastir University. The patients were reviewed with respect to parameters like number and anatomical localization of the cyst(s), radiological determination of the type of the cyst(s) (according to the guidelines published by WHO, 2003), clinical complications and need of benzimidazole treatment.

Forty CCE-patients had cured or stable disease with no clinical or radiological evidence of recurrence or remaining cyst activity through a follow-up period ranging between 1 and 5 years (Table 1). Five showed totally calcified hepatic cysts at their last time-point.

Fourteen NCCE-patients were still sick at the end of the study, despite an initial attempt to carry out 
curative surgery of the cysts: 12 of them finally presented active cysts and progressive disease (3 patients suffered from fissured lung cysts, 6 had liver cysts and 3 had multiple localizations, including liver/spleen for 1 patient and liver/lungs for 2 patients) at the end of the study period. Another 2 patients were initially considered as inoperable cases and were treated with albendazole only (Zentel $10 \mathrm{mg} / \mathrm{kg} /$ day) for 5 and 3 years, respectively. In both patients disseminated cysts were visualized upon radiological examination. All NCCE patients presented at least 1 intact/viable cyst at the end of the follow-up study period, as detected by radiological examination.

In summary, 54 patients were clustered into 2 different groups i.e. (A) cured or inactive hydatid disease cases (CCE; $n=40 / 54)$, where the hydatid cyst had disappeared following surgery or had fully calcified in 5 cases, and the other cases remaining inactive for the study period, and (B) cases with active CE (NCCE; $n=14 / 54$ ) who presented a progressive form of disease after an obviously unsuccessful surgical intervention, or where no surgery was possible. Sera were collected at various time-intervals ranging from 1 week to 60 months post-surgery, and then tested in both ELISA and immunoblotting.

\section{Antigens}

Crude hydatid fluid (CHF) was obtained in Sardinia by aspiration from fertile sheep liver cysts. Inclusion criteria for CHF was fertility, a clear fluid consistency and a protein concentration of $>0.95 \mathrm{mg}$ per $\mathrm{ml}$. The CHF was supplemented with $1 \% 100 \mathrm{~mm}$ PMSF (phenylmethyl sulfonyl fluoride) solution, and subsequently sedimented at $10000 \mathrm{~g}$ at $4{ }^{\circ} \mathrm{C}$ for $30 \mathrm{~min}$. The supernatant was stored at $-20^{\circ} \mathrm{C}$ until used for ELISA and immunoblotting.

\section{$S D S-P A G E$}

Parasite antigens were separated on a 5-20\% linear gradient polyacrylamide gel as described by Poretti et al. (1999), using reducing and non-reducing conditions in parallel for comparative purposes (Bio-Rad apparatus). $\mathrm{CHF}$, after thawing, was brought into $10 \mathrm{~mm}$ Tris- $\mathrm{HCl}$ with $10 \% \mathrm{SDS}$ and $9 \mathrm{M}$ urea, and heated either for $20 \mathrm{~min}$ at $65^{\circ} \mathrm{C}$ (nonreducing condition) or for $5 \mathrm{~min}$ at $100{ }^{\circ} \mathrm{C}$ with $5 \%$ $\beta$-mercaptoethanol (reducing condition). Proteins were loaded at a concentration of $150 \mu \mathrm{g} / \mathrm{gel}$, and the electrophoresis was done at $500 \mathrm{~V}$ for $2 \mathrm{~h}$ at $4{ }^{\circ} \mathrm{C}$.

\section{Immunoblotting}

Electrophoretically resolved proteins were transferred onto nitrocellulose membranes as previously described by Poretti et al. (1999). Nitrocellulose strips ( $3 \mathrm{~mm}$ wide) were then incubated with human sera diluted at $1: 100$ in phosphate-buffered saline containing $0.3 \%$ Tween and $5 \%$ skim milk powder overnight at $4{ }^{\circ} \mathrm{C}$; strips were then washed and incubated with goat anti-human IgG horseradish peroxidase conjugate (Sigma A6029; diluted 1 : 200) for $2 \mathrm{~h}$ at room temperature. Immunoreactive antigenic bands were visualized using 3,3'-diaminobenzidine tetrahydrochloride (DAB) and $0.03 \%$ $\mathrm{H}_{2} \mathrm{O}_{2}$. The main diagnostic bands yielded in the immunoblot carried out under reducing conditions were the $8,12,16,21$ and $37 \mathrm{kDa}$ bands. Under nonreducing conditions, bands that localized at $8,12,16$, 21,55 and $65 \mathrm{kDa}$ were considered as diagnostically relevant. In order to report a positive serology, at least 1 of the $\mathrm{AgB}$ components had to show up. These $\mathrm{AgB}$ subunits localized at 8 and $16 \mathrm{kDa}$ for both reducing and non-reducing conditions (Lightowlers and Gottstein, 1995).

\section{Enzyme linked immunosorbent assay (ELISA)}

Nunc Immulon ELISA microplate strips were coated with $100 \mu \mathrm{l}$ per well of CHF diluted in ELISA coating buffer $\left(0 \cdot 1 \mathrm{M} \mathrm{Na} \mathrm{HCO}_{3} / \mathrm{Na}_{2} \mathrm{CO}_{3}, \mathrm{pH} 9 \cdot 6\right.$, containing $0 \cdot 02 \% \mathrm{NaN}_{3}$ ) to a concentration of $10 \mu \mathrm{g} /$ ml. ELISA strips were washed 3 times with washing buffer (PBS, 3\% Tween 20) and blocked with blocking buffer containing $0.05 \%$ bovine haemoglobin and $0 \cdot 02 \%$ sodium azide in $\mathrm{PBS}, \mathrm{pH} 7 \cdot 2$. Sera were diluted $1: 100$ in blocking buffer, and alkalinephosphatase-labelled anti-human IgG conjugate (Sigma A 5403) was used at a 1:2500 dilution. All incubations were done at $37^{\circ} \mathrm{C}$ for $30 \mathrm{~min}$. Plates were finally washed 3 times and then incubated with the substrate for $15 \mathrm{~min}$. The reaction was stopped with $3 \mathrm{~m} \mathrm{NaOH}$. The absorbances (A) were measured at $405 \mathrm{~nm}$ using a microplate reader (Dynex Technologies Bioconcept). The results were expressed in arbitrary defined antibody units (AU), which relate antibody activity in the test serum to a positive reference serum with an arbitrary antibody activity of 100 AU (Gottstein et al. 1993). Mathematically, AU were defined by the following formula:

\section{Absorbance A405 nm of}

$\frac{\text { test serum }- \text { cut-off value* }}{\text { Absorbance A } 405 \text { nm of positive }}$
reference serum - cut-off value*

The cut-off value(*) was determined based upon a threshold determined by the mean of the respective $\mathrm{A}_{405 \mathrm{~nm}}$ values plus 3 standard deviations ( $c f$. Gottstein et al. 2001) of 100 blood donor sera, i.e. the $\mathrm{A}_{405 \mathrm{~nm}}$-values of negative sera were ranging within the $99 \%$ confidence limit of a healthy control population. When plotted, the respective $A_{405} \mathrm{~nm}$ values essentially represented a normal distribution. Inter-test and intra-test variations were assessed by determining the coefficients of variation for reference 
Table 2. Percentage of seropositivity determined by ELISA in 40 patients with CCE (A) and 14 NCCE patients (B) plotted against the follow-up time

(D0: serum samples collected before surgery and/or initiation of therapy; D7: sample collected 1 week after surgery, 1M: one month after, $6 \mathrm{M}$ : six months after, $12 \mathrm{M}$ : twelve months; and so on. *Numbers in parenthesis indicate number of cases examined $(P>0 \cdot 05)$.)

(A)

\begin{tabular}{|c|c|c|c|c|c|c|c|c|c|c|c|c|c|c|c|c|c|c|}
\hline \multirow[b]{2}{*}{$\mathrm{AU}$} & \multicolumn{2}{|c|}{$\begin{array}{l}\text { D0 } \\
(33)^{*}\end{array}$} & \multicolumn{2}{|c|}{$\begin{array}{l}\text { D7 } \\
(29)^{*}\end{array}$} & \multicolumn{2}{|c|}{$\begin{array}{l}1 \mathrm{M} \\
(31)^{*}\end{array}$} & \multicolumn{2}{|c|}{$\begin{array}{l}6 \mathrm{M} \\
(34)^{*}\end{array}$} & \multicolumn{2}{|c|}{$\begin{array}{l}12 \mathrm{M} \\
(30)^{*}\end{array}$} & \multicolumn{2}{|c|}{$\begin{array}{l}24 \mathrm{M} \\
(26)^{*}\end{array}$} & \multicolumn{2}{|c|}{$\begin{array}{l}36 \mathrm{M} \\
(15)^{*}\end{array}$} & \multicolumn{2}{|c|}{$\begin{array}{l}48 \mathrm{M} \\
(7)^{*}\end{array}$} & \multicolumn{2}{|c|}{$\begin{array}{l}60 \mathrm{M} \\
(7)^{*}\end{array}$} \\
\hline & $n$ & $\%$ & $n$ & $\%$ & $n$ & $\%$ & $n$ & $\%$ & $n$ & $\%$ & $n$ & $\%$ & $n$ & $\%$ & $n$ & $\%$ & $n$ & $\%$ \\
\hline $85-185$ & 13 & $39 \cdot 4$ & 18 & 62 & 22 & 71 & 18 & $52 \cdot 9$ & 8 & $26 \cdot 6$ & 5 & $19 \cdot 2$ & 2 & $13 \cdot 3$ & 1 & $14 \cdot 3$ & 1 & $14 \cdot 3$ \\
\hline $25-80$ & 5 & $15 \cdot 1$ & 5 & $17 \cdot 2$ & 3 & $9 \cdot 6$ & 8 & $23 \cdot 5$ & 13 & $43 \cdot 3$ & 12 & $46 \cdot 1$ & 4 & $26 \cdot 6$ & 1 & $14 \cdot 3$ & 0 & 0 \\
\hline $5-20$ & 3 & 9 & 1 & $3 \cdot 4$ & 1 & $3 \cdot 2$ & 2 & $5 \cdot 8$ & 3 & 10 & 3 & $11 \cdot 5$ & 5 & $33 \cdot 3$ & 3 & $42 \cdot 8$ & 3 & $42 \cdot 8$ \\
\hline$<1$ (Negative) & 12 & $36 \cdot 4$ & 5 & $17 \cdot 2$ & 5 & $16 \cdot 1$ & 6 & $17 \cdot 6$ & 6 & $23 \cdot 3$ & 6 & 23 & 4 & $26 \cdot 6$ & 2 & $28 \cdot 5$ & 3 & $42 \cdot 8$ \\
\hline Seropositivity & 21 & $63 \cdot 6$ & 24 & $82 \cdot 7$ & 26 & 84 & 28 & $82 \cdot 3$ & 24 & 80 & 20 & 77 & 11 & $73 \cdot 3$ & 5 & $71 \cdot 4$ & 4 & $57 \cdot 1$ \\
\hline
\end{tabular}

(B)

\begin{tabular}{|c|c|c|c|c|c|c|c|c|c|c|c|c|c|c|c|c|c|c|}
\hline \multirow[b]{2}{*}{$\mathrm{AU}$} & \multicolumn{2}{|c|}{$\begin{array}{l}\text { D0 } \\
(12)^{*}\end{array}$} & \multicolumn{2}{|c|}{$\begin{array}{l}\text { D7 } \\
(7)^{*}\end{array}$} & \multicolumn{2}{|c|}{$\begin{array}{l}\text { 1M } \\
(11)^{*}\end{array}$} & \multicolumn{2}{|c|}{$\begin{array}{l}6 \mathrm{M} \\
(12)^{*}\end{array}$} & \multicolumn{2}{|c|}{$\begin{array}{l}12 \mathrm{M} \\
(13)^{*}\end{array}$} & \multicolumn{2}{|c|}{$\begin{array}{l}24 \mathrm{M} \\
(11)^{*}\end{array}$} & \multicolumn{2}{|c|}{$\begin{array}{l}36 \mathrm{M} \\
(7)^{*}\end{array}$} & \multicolumn{2}{|c|}{$\begin{array}{l}48 \mathrm{M} \\
(3)^{*}\end{array}$} & \multicolumn{2}{|c|}{$\begin{array}{l}60 \mathrm{M} \\
(2)^{*}\end{array}$} \\
\hline & $n$ & $\%$ & $n$ & $\%$ & $n$ & $\%$ & $n$ & $\%$ & $n$ & $\%$ & $n$ & $\%$ & $n$ & $\%$ & $n$ & $\%$ & $n$ & $\%$ \\
\hline $85-185$ & 9 & 75 & 5 & $71 \cdot 4$ & 11 & 100 & 12 & 100 & 11 & $84 \cdot 6$ & 9 & $81 \cdot 8$ & 6 & $85 \cdot 7$ & 3 & 100 & 2 & 100 \\
\hline $25-80$ & 1 & $8 \cdot 3$ & 1 & $14 \cdot 3$ & 0 & 0 & 0 & 0 & 2 & $15 \cdot 4$ & 2 & $18 \cdot 1$ & 1 & $14 \cdot 3$ & 0 & 0 & 0 & 0 \\
\hline $5-20$ & 0 & 0 & 0 & 0 & 0 & 0 & 0 & 0 & 0 & 0 & 0 & 0 & 0 & 0 & 0 & 0 & 0 & 0 \\
\hline$<1$ (Negative) & 2 & $16 \cdot 6$ & 1 & $14 \cdot 3$ & 0 & 0 & 0 & 0 & 0 & 0 & 0 & 0 & 0 & 0 & 0 & 0 & 0 & 0 \\
\hline Seropositivity & 10 & $83 \cdot 3$ & 6 & $85 \cdot 7$ & 11 & 100 & 12 & 100 & 13 & 100 & 11 & 100 & 7 & 100 & 3 & 100 & 2 & 100 \\
\hline
\end{tabular}

negative and positive sera, all having been tested in triplicate on each test plate; variation of $\leqslant 15 \%$ was recorded, which is considered acceptable for immunological assays (Pfister et al. 1999). Since this latter finding was essentially the same as that described previously for the EgHF-ELISA (Gottstein et al. 1993), no modification was required for the present study.

\section{Protein concentration}

Protein concentrations were determined using the Bio-Rad Bradford protein assay and bovine plasma immunoglobulin as a standard.

\section{Statistical analyses}

The Epi Info 6 program was used to calculate the Chi-square-test for comparing the rates of seropositivity between each group of patients during each period of follow-up. $P \leqslant 0.05$ was considered as statistically significant.

\section{RESULTS}

\section{ELISA}

The post-treatment evolution of antibody concentrations was comparatively assessed in CCE cases versus NCCE patients. Antibody levels were arbitrarily clustered into high (85-185 AU), medium (25-80 AU), low (5-20 AU) and negative (<1AU). CCE patients who were cured by radical cyst removal or who finally presented 'stable' non-viable cysts showed different antibody kinetics than NCCE patients who presented active (viable) cyst(s) (Table 2) at the end of the study period. In CCE patients, antibody levels increased within the first 6 months post-surgery in most cases with 7 (Table 2A) initially seronegative $\mathrm{CE}$ patients becoming seropositive at 1 month post-surgery. Subsequently, in most patients antibody levels decreased progressively with time, 12 out of 40 patients (30\%) being seronegative at the end-point of the serodiagnostic investigation, which varied between 1 and 5 years post-surgery. In contrast, most NCCE patients maintained high antibody levels (>85 AU), with a few in the medium ( $>25$ AU) antibody concentration class. An actual decrease of antibody levels was not found for the whole study time-period of up to 5 years in these patients (Table $2 \mathrm{~B}$ ). With regard to the overall final serodiagnostic positivity of ELISA, $71.4 \%$ of the CCE patients were still seropositive at 4 years postsurgery and $57 \cdot 1 \%$ at 5 years post-surgery. Furthermore, 2 CCE patients, who had fully calcified (surgically non-resected) cysts, still showed high antibody concentrations of 106 and $95 \mathrm{AU}$ at 4 years post-surgery, and 3 patients had antibody levels of 84 , 39 and 84 AU after 2, 5 and 1 year post-surgery, 
(A)

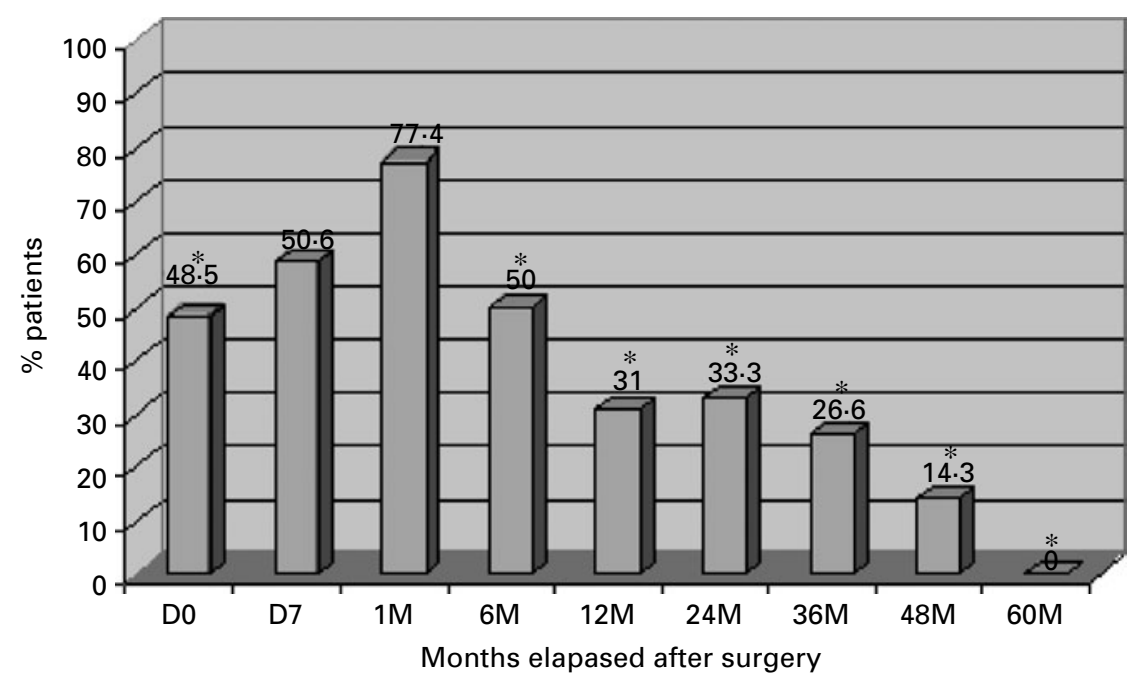

(B)

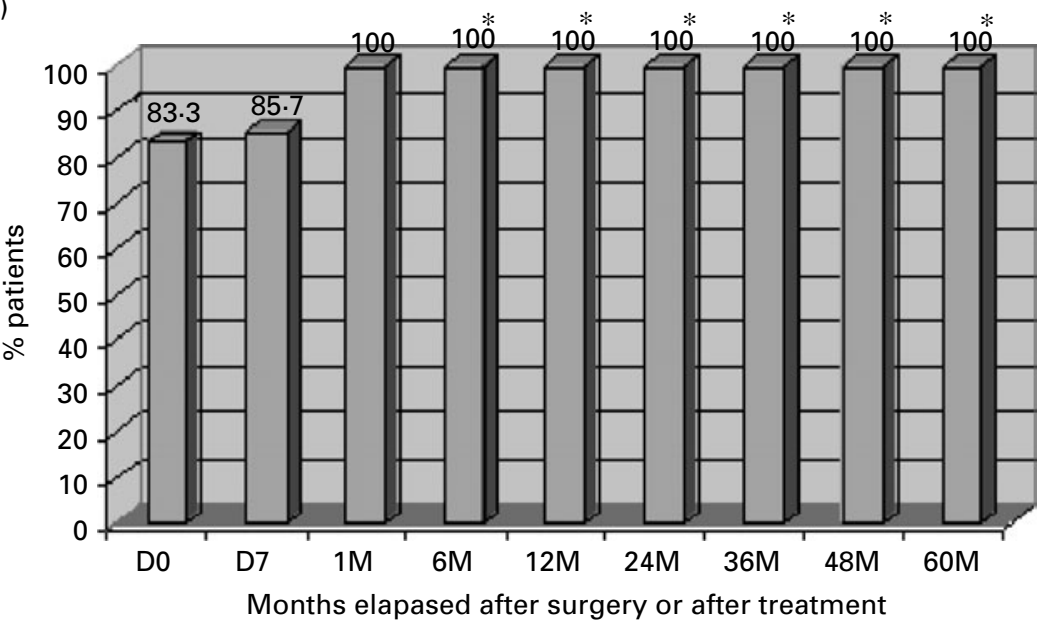

Fig. 1. Temporal evolution of AgB-band-recognition by immunoblotting in 30 CCE (A) and 14 NCCE patients (B) before and after treatment. Sera from 10 CCE patients with lung cysts, who were persistently seronegative by immunoblotting between day 0 and 5 years after diagnosis, were not included in this figure. D0: serum samples collected before surgery, D7: one week after surgery, $1 \mathrm{M}$ : one month after, $6 \mathrm{M}$ : six months after, 12 : twelve months after treatment, and so on. $* P<0 \cdot 05$ (between $\mathrm{A}$ and $\mathrm{B}$ ).

respectively. The decrease of antibody concentrations with time was considerably slower in these cases when compared to surgically treated CCE patients.

In NCCE patients, high antibody levels persisted in all of the patients (Table 2B). Overall, however, there was no statistically significant difference $(P>0.05)$ in seropositivity of samples from cured individuals (CCE) and those from NCCE patients at any time-point of the follow-up period.

With ELISA, 12 out of 34 (66.6\%) CCE patients treated by surgery alone reached seronegativity by their last serum sample. None of the 6 patients who received combined surgery/ABZ-treatment were negative at the end of the follow-up period. However, the differences in antibody concentrations between CCE patients who underwent combined surgery and ABZ-therapy versus those treated surgically were statistically not significant. Nevertheless, in both approaches a progressive decrease of antibody concentrations was observed (data not shown).

\section{Immunoblotting}

Immunoblotting profiles obtained with sera from 30 out of $40 \mathrm{CCE}$ and all NCCE patients showed an initial (day 0) strong recognition of 4 major bands localizing at $8,12,16$, and $21 \mathrm{kDa}$ for both reducing, and non-reducing conditions (Figs 1-3). Two of these bands ( 8 and $16 \mathrm{kDa}$ ) were attributed to $\mathrm{AgB}$ subcomponents as referenced by Lightowlers and Gottstein (1995). Another two bands at 55 and $65 \mathrm{kDa}$ appeared under non-reducing (Fig. 2) conditions, while a $37 \mathrm{kDa}$ band was visualized under reducing (Fig. 3) conditions. These $55 / 65 \mathrm{kDa}$ and $37 \mathrm{kDa}$ bands were also recognized by negative control sera, thus demonstrating a non-specificity of 
(A)

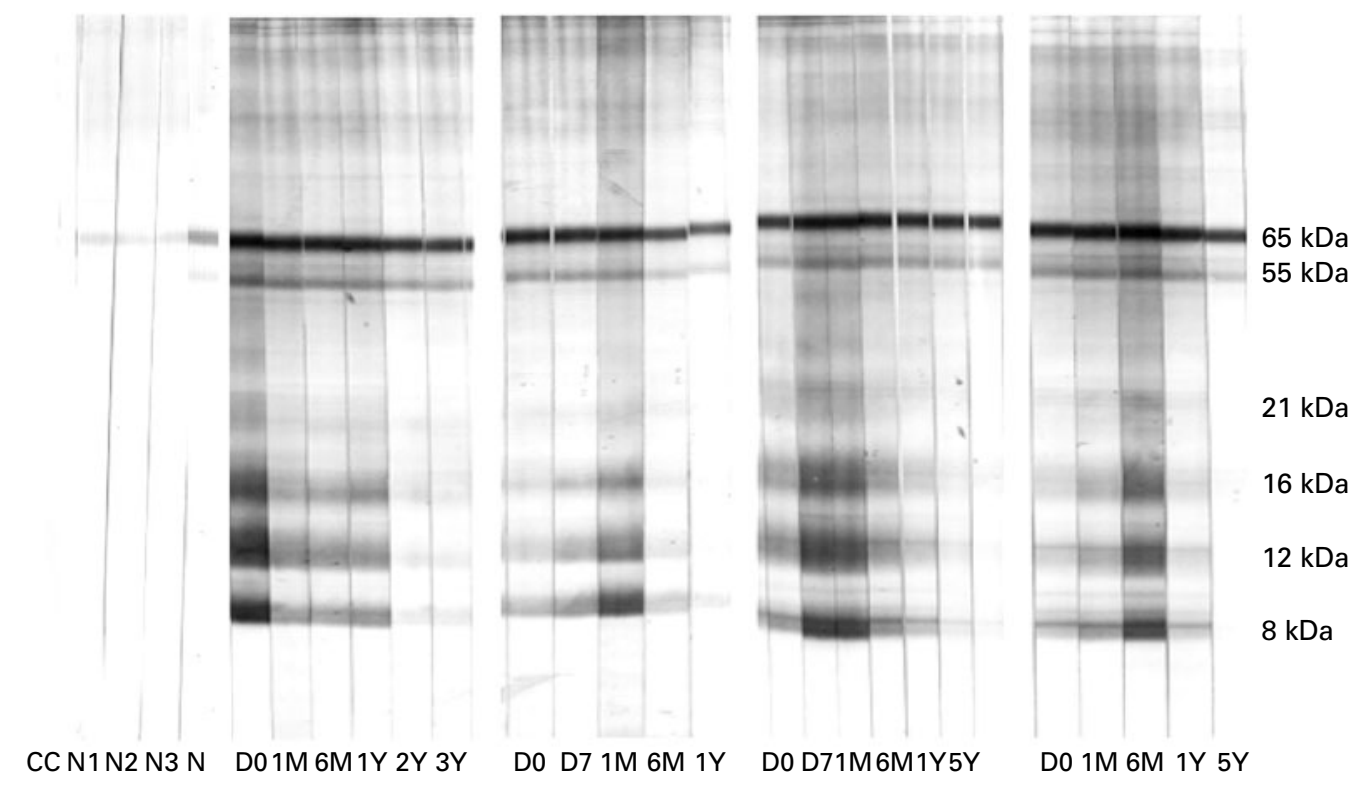

(B)
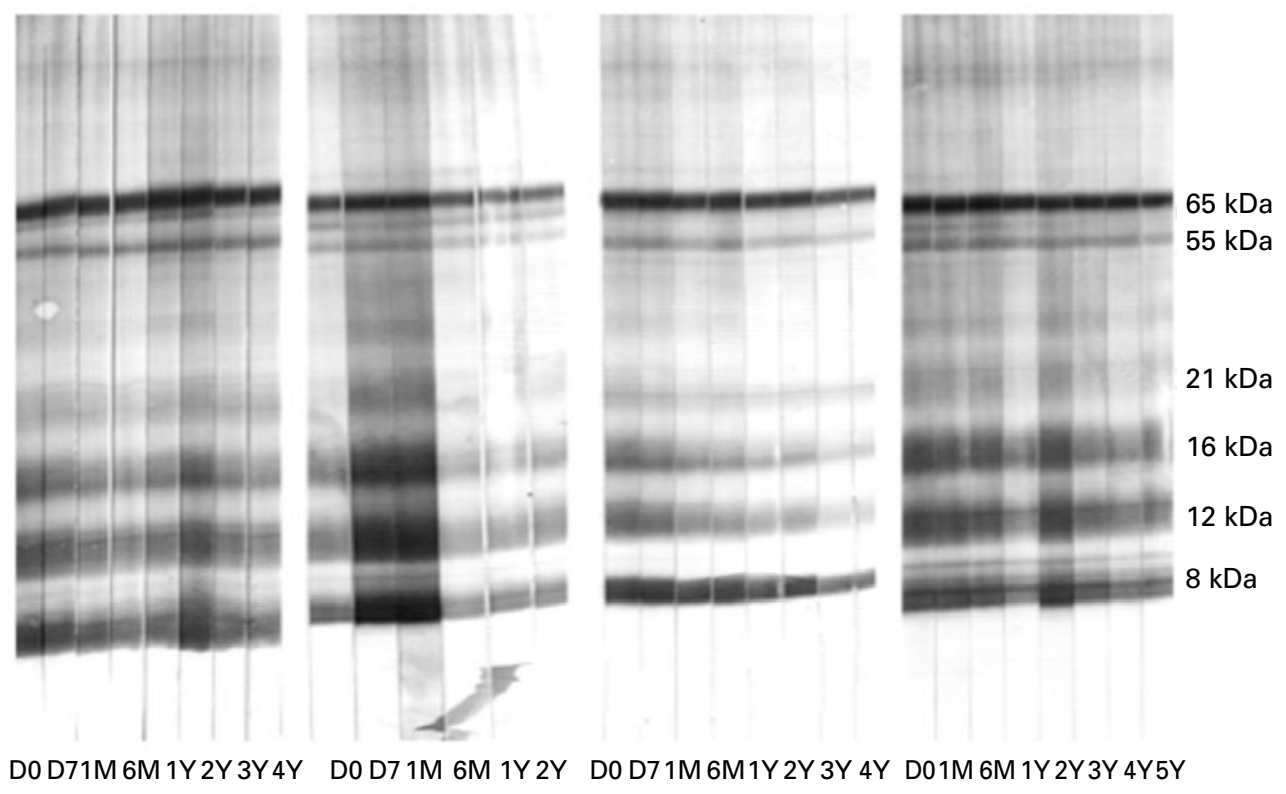

Fig. 2. Immunoblotting follow up, exemplified with sera from 4 out of 40 CCE (A) and 4 out of 14 NCCE patients (B) under non-reducing conditions. D0: serum samples collected before surgery, D7: one week after surgery, 1M: one month after, 6M: six months after, $1 \mathrm{Y}: 1$ year post surgery, $2 \mathrm{Y}: 2$ years, and so on. Four negative control sera (N1-N4) as well as a conjugate control (CC) are included in (A).

these signals. Clearly different patterns became evident between the two groups of patients over time. Sensitivity based on the detection of at least 1 of the AgB subcomponents, decreased sharply from $77 \cdot 4 \%$ to $50 \%$ within 1 month and 6 months, respectively, in CCE cases, and subsequently to $14 \cdot 3 \%$ at 4 years after surgical treatment (Fig. 1A). No detectable bands were observed 5 years post-surgery in these patients (Fig. 1A). However, in $5 \mathrm{CCE}$ patients whose clinical examination had indicated the presence of calcified cysts, and who were estimated as clinically cured from hydatidosis, at least 1 of the antigen $\mathrm{B}$ subcomponents remained immunoreactive during a relatively long time of follow-up. Interestingly, we noticed the complete absence of anti$\mathrm{AgB}$ antibody reactivity before surgery and during follow-up in 10 out of 18 patients with lung cysts. Four of these 10 cases were also negative in ELISA during the same period of follow-up, the other 6 ELISA-positive cases showed a progressive decrease of antibody levels during the follow-up period. In contrast to these CCE lung cases, NCCE patients, independent of the organ localization, showed a persistent recognition of $\mathrm{AgB}$ subcomponents that was still significantly high even 5 years post-treatment (Fig. 1B). At the time of diagnosis (day 0), high 
(A)
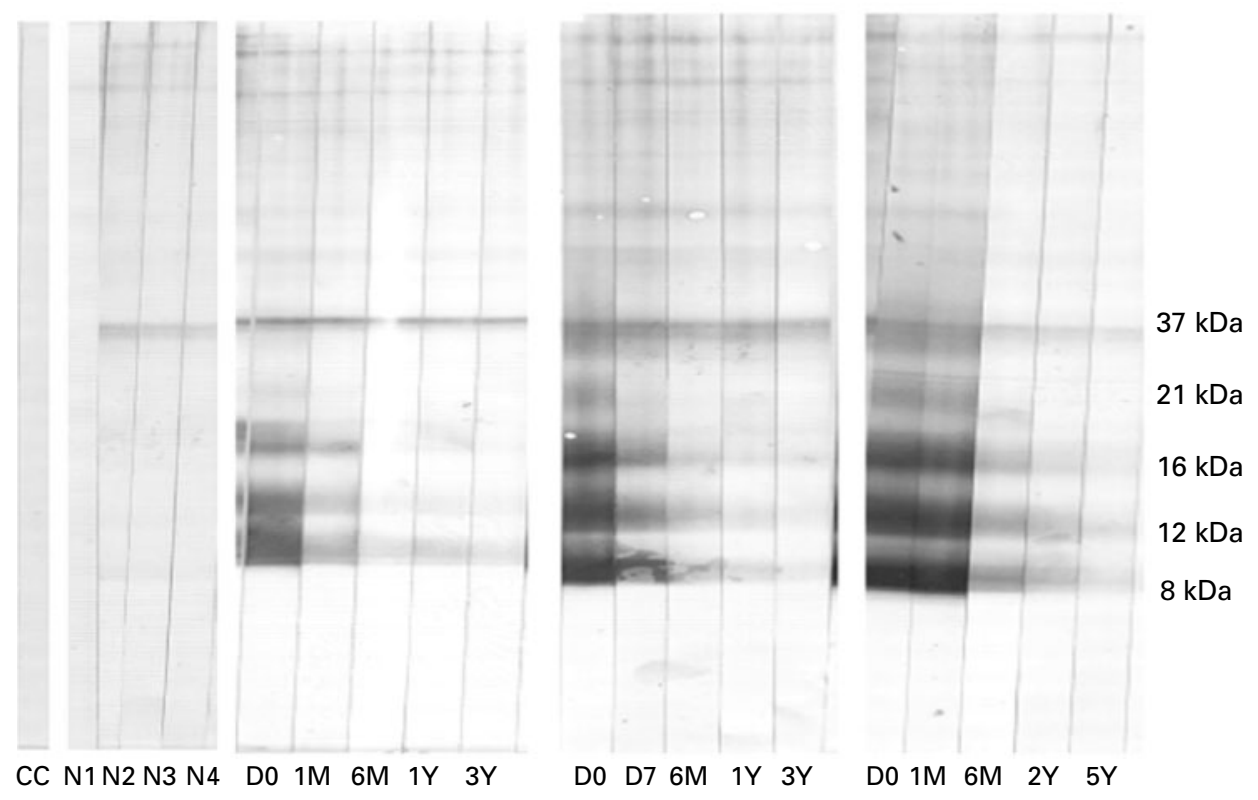

(B)
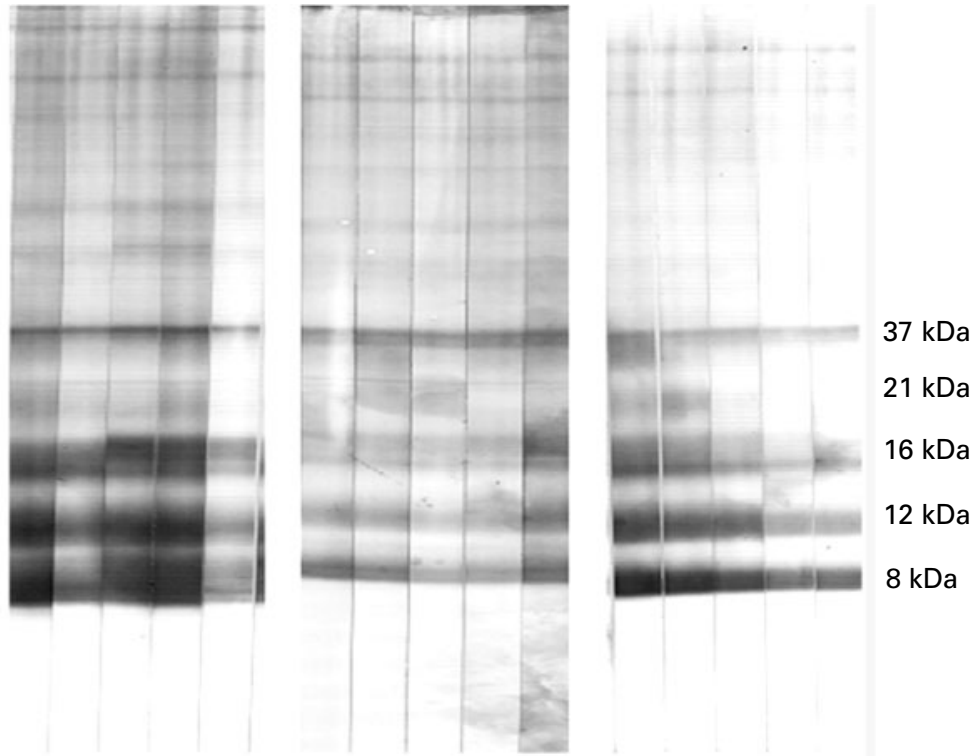

D0 1M 6M 2Y 4Y

D0 D7 $\quad 6 \mathrm{M} \quad 1 \mathrm{Y} \quad 3 \mathrm{Y}$

D0 1M 6M 3Y $5 Y$

Fig. 3. Immunoblotting follow up, exemplified with sera from 3 out of 40 CCE (A) and 3 out of 14 NCCE patients (B) under reducing conditions. D0: serum samples collected before surgery, D7: one week after surgery, 1M: one month after, 6M: six months after, 1Y: 1 year post surgery, 2Y: 2 years and so on. Four negative control sera (N1-N4) as well as a conjugate control (CC) are included in (A).

antibody concentrations were generally detected by ELISA in patients with liver cysts and in multiple cyst localizations including the lungs. Throughout subsequent follow-up, the progressive decrease of antibodies was more rapid for lung and liver localization than for multiple locations. Thus, seronegativity was reached at the end time-point of follow up in only 1 out of 11 multiple cyst localization ( $9 \%$ ) versus 7 out of 18 (39\%) lung cysts and 4 out of 11 $(36 \cdot 4 \%)$ liver cysts.

Statistically significant differences were observed between the two groups (CCE and NCCE) at day 0 (before surgery: $P=0 \cdot 04$ ) and starting from 6 months until 5 years follow up $(6 \mathrm{M} / P=0 \cdot 010)$, $\left(12 \mathrm{M} / P=10^{-4}\right),\left(24 \mathrm{M}, 36 \mathrm{M}, 48 \mathrm{M} / P=10^{-3}\right),(60 \mathrm{M} /$ $P=0 \cdot 02)$. Furthermore, CCE patients who were cured by surgery showed a progressive disappearance of the different antigen bands starting from 6 months post-surgery, as exemplified in Figs 2 and 3. Interestingly, in some cases, there was an earlier disappearance of the $16 \mathrm{kDa} \mathrm{AgB}$ subcomponent, while the $8 \mathrm{kDa}$ disappeared later.

No significant effect on the antibody binding activity in immunoblotting was observed when 
comparing surgery/ABZ-treatment versus surgery alone (data not shown), irrespective of the CCE or NCCE status. Nevertheless, CCE patients exhibited a slightly higher rate of seronegativity by immunoblotting than by ELISA, but the discriminating power was also no better when comparing the combined surgery/ABZ-treatment with surgery alone (4 immunoblot negatives out of 6 patients treated with surgery/ABZ versus 26 out of 34 patients only treated by surgery, respectively). The 2 NCCE patients who were only medically treated with ABZ exhibited no decrease in the banding pattern and no decrease in the band-staining intensity.

\section{ISCUSSION}

Hydatidosis is a cosmopolitan disease and is highly endemic in most of the Mediterranean countries. One of the characteristics of hydatid disease is the relatively frequent occurrence of relapses after surgery. Such relapses may be due to several reasons, predominantly as follows: (i) cyst (or cysts) has (have) been incompletely removed by surgery, or the cyst has ruptured, and spilling of hydatid fluid containing protoscolices occurred, causing secondary infection; (ii) cyst (or all the cysts) has (have) been completely removed as reported by the surgeon, but additional small, initially undetectable cysts were growing months or years after initial therapy; (iii) patients cured by surgery may putatively become reinfected months or years after successful therapy. However, such an event may be relatively unlikely, and is also controversially discussed, as protective immunity may prevent reinfection in former cured CE patients, but such protective immunity has not yet been really proven. Nevertheless, the relatively high frequency of relapses requires follow-up methods that are suitable for monitoring the radicality of surgical cyst resection or the viablity status of putatively remaining cyst material, including protoscolices. Follow-up sera from cured (CCE) and non-cured (NCCE) young hydatidosis patients treated by surgery were subjected to ELISA and immunoblot testing; both methods were based upon crude sheep hydatid fluid as a source of parasite antigen. Serological reactivities of $\mathrm{CCE}$ patients in ELISA increased during an initial 6-month period after surgery, followed later by a progressive decrease. In NCCE patients, a similar increase was observed for the first 6-month period, but the subsequent decrease was less pronounced. This difference between CCE and NCCE patients was not marked enough to allow a statistically significant differentiation between the two groups. These ELISA results are consistent with those found in other studies such as those published by Gottstein et al. (1986); Craig et al. (1986); Bulut et al. (2001) and Force et al. (1992). In contrast, Zarzoza et al.
(1999) reported a higher rate of sera becoming seronegative in their study $(25.9 \%$ and $16.6 \%$ of cured patients at 4 and 5 years post-surgery, respectively). However, this effect may be attributable to the fact that only cases of pulmonary cyst localization were investigated. It has been shown that lung cysts yield lower serological responses than hepatic ones (Babba et al. 1994; Force et al. 1992). Immunoblotting data demonstrated that there was a decrease in antibody reactivities with regard to the 8 and $16 \mathrm{kDa} \mathrm{AgB}$ subunits, as seen as a $50 \%$ recognition rate at 6 months and a $14 \cdot 3 \%$ recognition rate at 4 years postsurgery. None of the sera reacted with these bands at 5 years post-surgery. All non-cured cases (100\%) showed a strong persistence in reactivities with these bands during the follow up. Thus, our results are similar to those of Doiz et al. (2001), in which reactivities with $\mathrm{AgB}$ fractions $(12,16,20 \mathrm{kDa})$ disappeared within 11 months of treatment, whereas non-cured patients remained seropositive for a 3 -year period post-surgery in $50 \%, 75 \%$ and $75 \%$ for the 12,16 and $20 \mathrm{kDa}$ bands, respectively. $\mathrm{AgB}$ exhibits an improved diagnostic value respective to infection risk factors (Hernandez et al. 2005). Therefore, the assessment of purified antigens such as the synthetic $\mathrm{AgB}$ peptide published by GonzalesSapienza et al. (2000) for the follow-up of CE patients may be of interest.

In our study, $10 \mathrm{CE}$ patients presented both negative ELISA and immunoblot findings for the whole study period. Seronegativity in cases of lung cyst localization had for long been recognized as a diagnostic problem (Lightowlers and Gottstein, 1995), and this problem also holds true for posttreatment follow-up studies. The generally accepted explanation for this phenomenon is a marked separation of the cysts from the surrounding pulmonal tissue and a consequent weak release of parasite metabolites (antigens) into the pulmonal circulation, resulting in a greatly diminished antigen stimulation and host immune response at the immunologically competent sites in the lungs. The consequence is that such cases should be monitored by imaging techniques rather than by serology. With regard to ABZtherapy, ELISA and immunoblotting yielded no significant differences between sera from CCE or NCCE patients who underwent combined surgery and ABZ-therapy or those who were operated and received no therapy.

In conclusion, ELISA and immunoblotting have demonstrated their relative usefulness in the post-therapeutic serological follow-up of patients presenting different courses of disease, i.e. cure or non-cure as monitored by the occurrence of relapses or persitence of symptoms during a 4-5 year period after initiation of treatment. Immunoblotting appears to be the test that best reflects the evolution of disease after curative surgery, since it becomes negative with regard to $\mathrm{AgB}$ banding reactivity, 
the effect starting from 6 months post-surgery. However, the lack of sensitivity of immunoblotting in certain cases of lung cyst localization limits its employment in these cases. Physical imaging examinations are also very useful in predicting cyst evolution, since it has been shown to be more sensitive than serology (Babba et al. 1994). This reinforces the necessity to combine both serology and imaging procedures for optimal monitoring of cystic echincoccosis/hydatidosis.

In the light of our findings, we suggest that immunoblotting should be carried-out to follow-up operated hydatidosis patients at least 6 months and 12 months post-operatively, respectively, and subsequently once a year for a minimum period of 4 years, using the interpretation criteria as outlined above.

Finally, the search for new approaches to improve respective serological tools is still needed. Using other sources of antigens such as protoscoleces or recombinant proteins may be an option to develop serological means with an improved prediction of the disease activity. Furthermore, we anticipate a more detailed analysis of non-cured patients, who will have to be grouped according to different means of relapses (as outlined above). The search for parameters that could discriminate between such subgroups of NCCE patients may provide additional useful information for clinicians to facilitate decisive selection of further treatment strategies to be implemented for such patients.

This work was supported by the Swiss National Science Foundation (grant no. 31-111780/1), by the Hans-Sigrist Foundation (grant no. 31-111780/1) and by the Tunisian High Education Ministry (grant no.65/05).

\section{REFERENCES}

Babba, H., Messedi, A., Masmoudi, S., Zribi, M., Grillot, R., Ambroise Thomas, P., Beyrouti, I. and Sahnoun, Y. (1994). Diagnosis of human hydatidosis: comparison between imagery and six serologic techniques. American Fournal of Tropical Medicine and Hygiene 50, 64-68.

Bulut, V., Ilhan, F., Yucef, A. Y., Onal, S. and Godekmerdan, A. (2001). Immunological follow up of hydatid cyst cases. Memórias do Instituto Oswaldo Cruz 96, 669-671.

Craig, P. S., Zeyhl, E. and Romig, T. (1986). Hydatid disease research and control in Turkana II. The role of the immunological techniques for the diagnosis of hydatid disease. Transactions of the Royal Society of Tropical Medicine and Hygiene 80, 183-192.

Dincer, S. I., Demir, A., Sayar, A., Gunluoglu, M. Z., Kara, H. V. and Gurses, A. (2006). Surgical treatment of pulmonary hydatid disease: a comparison of children and adults. Fournal of Pediatric Surgery 41, 1230-1236.

Doiz, O., Benito, R., Sbihi, Y., Osuna, A., Clavel, A. and Gomez Lus, R. (2001). Western blot applied to the diagnosis and post treatment monitoring of human hydatidosis. Diagnostic Microbiologic and Infectious Disease 41, 139-142.

Durakbasa, C. U., Tireli, G. A., Sehiralti, V., Sander, S., Tosyali, A. N. and Mutus, M. (2006). An audit on pediatric hydatid disease of uncommon localization: incidence diagnosis, surgical approach, and outcome. Fournal of Pediatric Surgery 41, 1457-1463.

Eckert, J., Conraths, F. J. and Tackmann, K. (2000). Echinococcosis: an emerging or reemerging zoonosis? International Fournal for Parasitology 30, 1283-1294.

Force, L., Torres, J. M., Carrillo, A. and Busca, J. (1992). Evaluation of eight serological tests in the diagnosis of human echinococcosis and follow-up. Clinical Infectious Disease 15, 473-480.

Franchi, C., Di Vico, B. and Teggi, A. (1999). Long-term evaluation of patients with hydatidosis treated with benzimidazole carbamates. Clinical Infectious Disease 29, 304-309.

Gadea, I., Ayala, G., Diago, M. T., Cunat, A. and Garcia De Lomas, J. (2000). Imunological diagnosis of human hydatid cyst relapse: utility of the enzyme linked imunoelectrotransfer blot and discriminant analysis. Clinical and Diagnostic Laboratory Immunlogy 7, 549-552.

Gonzales-Sapienza, G., Lorenzo, C. and Nieto, A. (2000). Improved immunodiagnosis of cystic hydatid disease by using a synthetic peptide with higher diagnostic value than that of its parent protein, Echinococcus granulosus antigen B. Fournal of Clinical Microbiology 38, 3979-3983.

Gottstein, B., Shantz, P. M., Todorov, T., Saimot, A. G. and Jacquier, P. (1986). An international study of the serological differential diagnosis of human cystic and alveolar echinococcosis. Bulletin of the World Health Organization 64, 101-105.

Gottstein, B., Jacquier, P., Bresson-Hadni, S. and Eckert, J. (1993). Improved primary immunodiagnosis of alveolar echinococcosis in humans by an enzymelinked immunosorbent assay using the $\mathrm{Em} 2^{\text {plus }}$-antigen. Fournal of Clinical Microbiology 31, 373-376.

Gottstein, B., Saucy, F., Deplazes, P., Reichen, J., Demierre, G., Zürcher, C., Busato, A. and Pugin, P. (2001). Is a high prevalence of Echinococcus multilocularis in wild and domestic animals associated with increased disease incidence in humans? Emerging Infectious Diseases 7, 408-412.

Hernandez, A., Cardozo, G., Dematteis, S., Baz, A., Trias, N., Hunez, H., Nunez, H., Barrague, A., Lopez, L., Fuentes, J., Lopez, O. and Ferreira, C. (2005). Cystic echinococcosis: analysis of the serological profile related to the risk factors in individuals without ultrasound liver changes living in an endemic area of Tacuarembo, Uruguay. Parasitology 130, 455-460.

Lawn, S. D., Bligh, J., Craig, P. S. and Chiodini, P. L. (2004). Human cystic echinococosis: evaluation of post-treatment serologic follow-up by IgG subclass antibody detection. American Fournal of Tropical Medicine and Hygiene 70, 329-335.

Lightowlers, M. W. and Gottstein, B. (1995), Echinococcosis /Hydatidosis: antigens, immunological and molecular diagnosis. In Echinococcus and Hydatid Disease (ed. Thompson, R. C. A. and Lymbery, A. J.), pp. 355-410. CAB International, Oxon. 
McManus, D. P., Zhang, W., Li, J. and Bartley, P. B. (2003). Echinococcosis. Lancet 362, 1295-1304.

Ministère de la Santé Publique. (1993). L'incidence chirurgicale de l'hydatidose, en Tunisie (1988-1992). D. S. S. B. Direction des Soins de Santé de Base, Ministère de la Santé Publique, Tunis.

Moosa, R. A. and Abdel-Hafez, S. K. (1994). Serodiagnosis and seroepidemiology of human unilocular hydatidosis in Jordan. Parasitology Research 80, 664-671.

Nasrieh, M. A. and Abdel-Hafez, S. K. (2004). Echinococcus granulosus in Jordan: assessment of various antigenic preparations for use in the serodiagnosis of surgically confirmed cases using enzyme assays and the indirect haemagglutination test. Diagnostic Microbiology and Infectious Disease 48, 117-123.

Oudni-M'Rad, M., M'Rad, S., Gorcii, M., Mekki, M., Belguith, M., Harrabi, I., Nouri, A., Azeiz, R., Mezhoud, H. and Babba, H. (2007). Cystic echinococcosis in children in Tunisia: fertility and case distribution of hydatid cysts. Bulletin de la Société de Pathologie Exotique 100, 10-13.

Pawlowski, Z. S., Eckert, J., Vuitton, D. A., Amman, R. W. P., Kern, P., Craig, P. S., Dar, K. F., De Rosa, F., Filice, C., Gottstein, B., Grimm, F., Macpherson, C. N. L., Todorov, J., Uchino, W., Von Sinner, W. and Wen, H. (2001). Echinococcosis in humans: clinical aspects, diagnosis and treatment. In $W H O / O I E$ Manual on Echinococcosis in Humans and Animals : Public Health Problem of Global Concern. World Organization for Animal Health (ed. Eckert, J., Gemmel, M. A., Meslin, F.-X. and Pawlowski, Z. S.), pp. 20-66. Paris, France.

Pfister, M., Gottstein, B., Cerny, T. and Cerny, A. (1999). Immunodiagnosis of echinococcosis in cancer patients. Clinical Microbiology and Infection $\mathbf{5}$, 693-697.
Poretti, D., Felleisen, E., Grima, F., Pfister, M., Teuscher, F., Zuercher, C., Reichen, J. and Gottstein, B. (1999). Differential immunodiagnosis of human cystic hydatid disease and other cross reactive pathologies. American Fournal of Tropical Medicine and Hygiene 60, 193-198.

Ravinder, P. T., Parija, S. C. and Rao, K. S. (1997). Evaluation of human hydatid disease before and after surgery and chemotherapy by demonstration of hydatid antigens and antibodies in serum. Fournal of Medical Microbiology 46, 859-864.

Rigano, R., Ioppolo, S., Ortona, E., Margutti, P., Profumo, E., Ali, M. D., Di Vico, B., Teggi, A. and Siracusano, A. (2002). Long term serological evaluation of patients with cystic echinococcosis treated with benzimidazole carbamates. Clinical and Experimental Immunology 129, 485-492.

World Health Organization (2001). Echinococcosis in humans: clinical aspects, diagnosis and treatment. In WHO/OIE Manual on Echinocccosis in Humans and Animals : a Public Health Problem of Global Concern (ed. Eckert, J., Gemmel, M. A., Meslin, F.-X. and Pawlowski, Z. S.), pp. 20-60. WHO. Geneva.

World Health Organization Informal Working Group (2003). International classification of ultrasound images in cystic echinococcosis for application in clinical and field epidemiological settings. Acta Tropica 85, 253-261.

Zarzoza, M. P., Orduna, A., Gutierrez, P., Alonso, P., Cuervo, M., Prado, A., Bratos, M. A., Garcia Yuste, M., Ramos, G. and Torres, A. (1999). Evaluation of six serological tests in diagnosis and postoperative control of pulmonary hydatid disease patients. Diagnostic and postoperative control of pulmonary hydatid disease patients. Diagnostic Microbiolology and Infectious Disease 35, 255-262. 